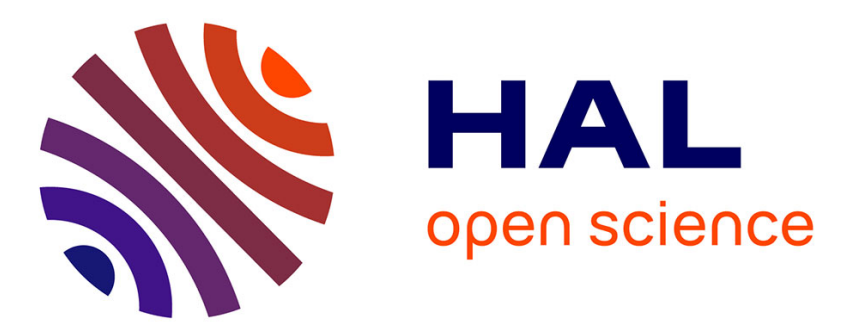

\title{
Addition of tracers into the polypropylene in view of automatic sorting of plastic wastes using X-ray fluorescence spectrometry
}

Feliks Bezati, Daniel Froelich, Valérie Massardier, Elisabeth Maris

\section{- To cite this version:}

Feliks Bezati, Daniel Froelich, Valérie Massardier, Elisabeth Maris. Addition of tracers into the polypropylene in view of automatic sorting of plastic wastes using X-ray fluorescence spectrometry. Waste Management, 2010, 30, pp.591-596. 10.1016/j.wasman.2009.11.011 . hal-01026503

\section{HAL Id: hal-01026503 https://hal.science/hal-01026503}

Submitted on 4 Sep 2017

HAL is a multi-disciplinary open access archive for the deposit and dissemination of scientific research documents, whether they are published or not. The documents may come from teaching and research institutions in France or abroad, or from public or private research centers.
L'archive ouverte pluridisciplinaire HAL, est destinée au dépôt et à la diffusion de documents scientifiques de niveau recherche, publiés ou non, émanant des établissements d'enseignement et de recherche français ou étrangers, des laboratoires publics ou privés. 


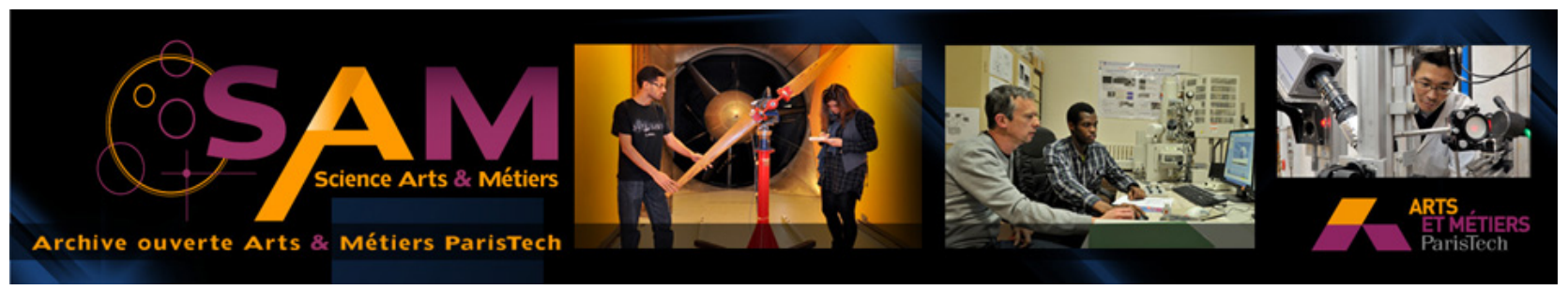

\section{Science Arts \& Métiers (SAM)}

is an open access repository that collects the work of Arts et Métiers ParisTech researchers and makes it freely available over the web where possible.

This is an author-deposited version published in: http://sam.ensam.eu

Handle ID: .http://hdl.handle.net/10985/8369

\section{To cite this version :}

Daniel FROELICH, Elisabeth MARIS, Valérie MASSARDIER, Feliks BEZATI - Addition of tracers into the polypropylene in view of automatic sorting of plastic wastes using $X$-ray fluorescence spectrometry - Waste Management n³0, p.591-596 - 2009 


\title{
Addition of tracers into the polypropylene in view of automatic sorting of plastic wastes using X-ray fluorescence spectrometry
}

\author{
F. Bezati ${ }^{\mathrm{a}, \mathrm{b}, *}$, D. Froelich ${ }^{\mathrm{a}}$, V. Massardier ${ }^{\mathrm{b}}$, E. Maris $^{\mathrm{a}}$ \\ a MAPIE-Laboratoire de Modélisation, Analyse et Prévention des Impacts Environnementaux, Institut ENSAM Savoie Technolac, 4 Rue du Lac Majeur, \\ F-73375 Le Bourget du Lac Cedex, France \\ ${ }^{\mathrm{b}}$ IMP/LMM-Ingénierie des Matériaux Polymères - Laboratoire des Matériaux Macromoléculaires UMR 5223, INSA de Lyon Bat. Jules VERNE, \\ 17, rue Jean Capelle F-69621 Villeurbanne Cedex, France
}

\section{A R T I C L E I N F O}

Article history:

Accepted 14 November 2009

Available online 16 December 2009

\begin{abstract}
A B S T R A C T
This study focused on the detection of rare earth oxides, used as tracers for the identification of polymer materials, using XRF (X-ray fluorescence) spectrometry. The tests were carried out in a test system device which allows the collection of static measurements of the samples' spectrum through the use of energy dispersive X-ray fluorescence technology.

A sorting process based on tracers added into the polymer matrix is proposed in order to increase sorting selectivity of polypropylene during end-of-life recycling. Tracers consist of systems formed by one or by several substances dispersed into a material, to add a selective property to it, with the aim of improving the efficiency of sorting and high speed identification.

Several samples containing rare earth oxides $\left(\mathrm{Y}_{2} \mathrm{O}_{3}, \mathrm{CeO}_{2}, \mathrm{Nd}_{2} \mathrm{O}_{3}, \mathrm{Gd}_{2} \mathrm{O}_{3}, \mathrm{Dy}_{2} \mathrm{O}_{3}, \mathrm{Er}_{2} \mathrm{O}_{3}\right.$ and $\left.\mathrm{Yb}_{2} \mathrm{O}_{3}\right)$ in different concentrations were prepared in order to analyse some of the parameters which can influence the detection, such as the concentration of tracers, the acquisition time and the possible overlapping among the tracers. This work shows that by using the XRF test system device, it was possible to detect 5 of the 7 tracers tested for $1 \mathrm{~min}$ exposure time and at a concentration level of $1000 \mathrm{ppm}$. These two parameters will play an important role in the development of an industrial device, which indicates the necessity of further works that needs to be conducted in order to reduce them.
\end{abstract}

\section{Introduction}

Thanks to their technical and economical performances, plastics cover today a large and varied range of uses (packaging, building, automobile, electrical and electronic equipments, etc.). Once they have completed their task, the objects become wastes and so it is necessary to manage their future.

In order to reduce the growing volume of plastic waste, the management of their treatment has become a high priority on the political, economical and environmental agenda of all industrialized nations.

To complete the European Commission directives, dealing with the management of the end-of-life post-consumer products (European Parliament, 2000, 2003), concerned manufacturers are encouraged to develop solutions which reduce the impact of their

\footnotetext{
* Corresponding author. Address: MAPIE-Laboratoire de Modélisation, Analyse et Prévention des Impacts Environnementaux, Institut ENSAM Savoie Technolac, 4 Rue du Lac Majeur, F-73375 Le Bourget du Lac Cedex, France. Tel.: +33 (0) 472436003 ; fax: +33 (0) 472438527.

E-mail address: feliks.bezati@ensam.eu (F. Bezati).
}

end-of-life products, and to have a real policy of raw resource management based on a relevant recycling plan. Furthermore, the European legislations and directives (Zoboli, 1998) require producers to use a fraction of their recycled material in their final product.

Currently, the energetic recovery of plastic wastes is achieved through easy options such as incineration, which is often neither economically profitable nor respectful to the environment (Olofsson, Sundberg, Sahlin, 2005; Patel et al., 1998). However, it is generally difficult to recycle these materials because of their contamination with other plastic materials that are incompatible with each other. Therefore, it is necessary to improve technologies such as the sorting of polymer materials so as to make their recycling profitable. For an economically efficient recycling of polymer materials, waste plastics need to be sorted cheaply and automatically into individual types and grades (Froelich et al., 2007).

Techniques based on optical spectroscopy, such as infrared reflection/absorption (Alam, Stanton, Hebner, 1994; Florestan et al., 1994; Moore, 1999) have reached their limits. This technique is not applicable to dark plastics of automotive parts; it cannot identify different grades of the same polymers and cannot be used if the surface of the plastic wastes is wet. 
The technique of high resolution imaging using X-rays is limited to the separation of PVC from PET (Kenny and Bruner, 1994) and the elimination of PVC and brominated aromatic compounds contained in electronic waste and substituted combustibles. In the automobile recycling industry this technique is limited to the identification of heavy metals contained in aluminium.

All the above methods do not use a tracer in order to facilitate detection and sorting. In early 1992, Ahmad (1992) developed a new concept of identification of plastics by incorporating a fluorescent tracer into the polymers and giving them fluorescence signatures in Ultra Violet spectroscopy. Recently, he also described a new technology for automatic sorting of plastics, based upon optical identification of fluorescence signatures of dyes, incorporated into such materials in trace concentrations (Ahmad, 2004). The conclusion of this research was that the speed and purity of sorting was limited by the mechanical singulation inadequacy in the conveyor system at high speeds.

The use of tracers is also found in the companies specializing in magnetic sorting. For example, Eriez has filed a patent (Mankosa and Luttrell, 2005) on a magnetic sorting process of polymers in which a magnetic substance is incorporated. The advantage of the magnetic detection is the lack of sensitivity regarding the additives contained in the polymers. However, the magnetic tracer system required amounts of tracers which are of the order of the percent and these quantities could engender homogenisation problems and affect the mechanical properties of the polymer.

The challenge of overcoming the inefficiency of existing sorting technologies associated with the identification of the black plastics has led to the development of new methods of identification of polymeric materials.

The principal objectives of this work are to prove the detection of tracers (rare earth oxides) added to polypropylene through the use of X-ray fluorescence spectrometry and to evaluate some of the parameters which can influence the detection, such as the concentration of tracers, the time of detection and the possible overlapping interferences among the tracers. Dispersion of such selected tracers in thermoplastic polymers, during the compounding process, will, therefore, allow automatic sorting and increase sorting selectivity of the plastic wastes during end-of-life recycling.

\section{The identification of tracers}

It turns out that the effectiveness of sorting and in particular the speed of identification of plastic wastes can be improved by the use of a tracer system giving a unique signature to each type and grade of polymer. In the detection system presented below, the excitation of the tracers will be achieved through the use of an X-ray source and detection by X-ray fluorescence spectrometry.

This work of identification technology was firstly proposed by Ahmad (Ahmad, 2000; Simmons et al., 1998), who used fluorescent tracers emitting in ultraviolet spectrometry.

The identification system is based on the incorporation of very small quantities of one or more substances emitting in X-ray fluorescence - a "tracer" - into the plastics requiring identification. The concentration of the tracers must be in the range of 100 $1000 \mathrm{ppm}$, in order not to influence the properties of the polymer matrix.

Due to the great diversity of the nature of plastics, including the types of polymers, as well as the grades, the additives and colorants, it is not practical to have a tracer for each potential variant. To overcome this, tracers can be used in a matrix, such that each combination corresponds to a type, grade or additive (Fig. 1). For example, theoretically, by using only 4 tracers, it is possible to identify $15\left(2^{4}-1\right)$ variations of different plastics.

The identification is carried out by exciting the plastics using an $\mathrm{X}$-rays source. This radiation is absorbed by the tracers, who are excited to higher atomic energy levels. Each tracer emits a unique radiation in X-ray fluorescence, which depends on the atomic number of the element. The detection system, coupled with a data processing system, detects the emitted radiation and identifies the signature of the tracer, and thus the nature of the polymer matrix.

\section{Experimental part}

\subsection{Materials}

ISPLEN PP $050 \mathrm{G} 1 \mathrm{E}$ is a medium melt flow rate polypropylene homopolymer particularly formulated and adapted for injection moulding and extrusion applications. It is intended for applications that require good impact resistance balanced with high stiffness. The original pellets have a melt mass-flow rate of $5.8 \mathrm{~g} / 10 \mathrm{~min}$ $\left(2.16 \mathrm{~kg}\right.$ at $\left.230{ }^{\circ} \mathrm{C}\right)$ and a density of $0.905 \mathrm{~g} / \mathrm{cm}^{3}$.

The rare earth oxides used as tracers are given in Table 1 . The rare earth oxides were chosen as tracers because they satisfy the required specifications (Hedrick, 1988; Maestro and Huguenin, 1995; Morteani, 1991). They are compatible, not abrasive and stable in the environment of evolution. They are also non toxic (Lauwerys et al., 2007; Peltier, 1986) during their application and use.

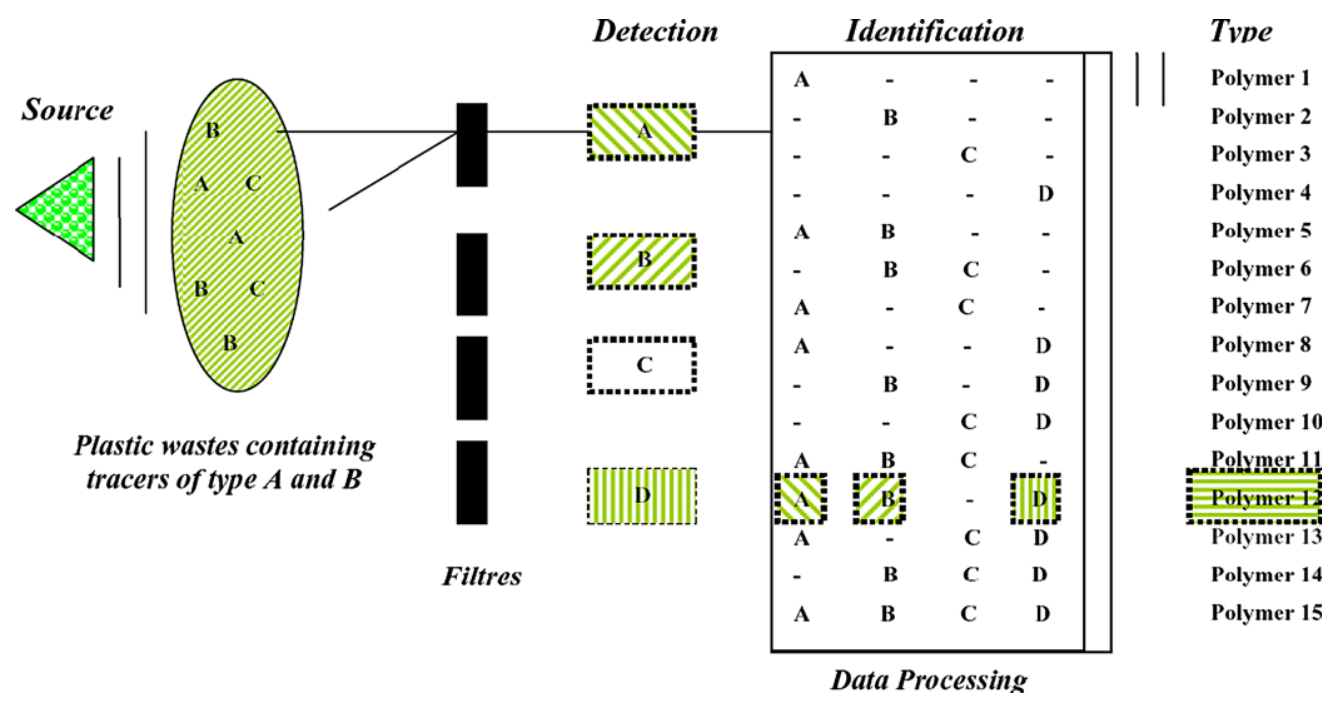

Fig. 1. Principle of optical identification by binary code generated from X-ray fluorescent tracers. 
Table 1

Materials specifications.

\begin{tabular}{|c|c|c|c|c|c|c|}
\hline Materials & Chemical name & Supplier & Mean particle diameter $(\mu \mathrm{m})$ & Density $\left(\mathrm{g} / \mathrm{cm}^{3}\right)$ & Melting point $\left({ }^{\circ} \mathrm{C}\right)$ & Toxicity $\left(\mathrm{LD}_{50}{ }^{*}\right)$ \\
\hline $\mathrm{PP}$ & Polypropylene & REPSOL & 2000 & 0.905 & 167 & - \\
\hline $\mathrm{Y}_{2} \mathrm{O}_{3}$ & Yttrium oxide & RHODIA & 2.250 & 5 & 2415 & $>5000 \mathrm{mg} / \mathrm{kg}$ \\
\hline $\mathrm{CeO}_{2}$ & Cerium oxide & RHODIA & 2.250 & 7.3 & 1950 & $>5000 \mathrm{mg} / \mathrm{kg}$ \\
\hline $\mathrm{Nd}_{2} \mathrm{O}_{3}$ & Neodymium oxide & AMPERE & 3.500 & 7.24 & 2272 & $>1000 \mathrm{mg} / \mathrm{kg}$ \\
\hline $\mathrm{Gd}_{2} \mathrm{O}_{3}$ & Gadolinium oxide & RHODIA & 1.850 & 7.4 & 2340 & $>1000 \mathrm{mg} / \mathrm{kg}$ \\
\hline $\mathrm{Dy}_{2} \mathrm{O}_{3}$ & Dysprosium oxide & RHODIA & 2.250 & 7.8 & 2340 & $>1000 \mathrm{mg} / \mathrm{kg}$ \\
\hline $\mathrm{Er}_{2} \mathrm{O}_{3}$ & Erbium oxide & AMPERE & 8.200 & 8.6 & 2355 & $>1000 \mathrm{mg} / \mathrm{kg}$ \\
\hline $\mathrm{Yb}_{2} \mathrm{O}_{3}$ & Ytterbium oxide & AMPERE & 1.000 & 9.2 & 2346 & $>1000 \mathrm{mg} / \mathrm{kg}$ \\
\hline
\end{tabular}

Median lethal dose $\left(\mathrm{LD}_{50}\right)$ of a toxic substance is the dose required to kill half the members of a tested population.

Regarding the detection method, they have a high atomic number, facilitating their detection in X-ray fluorescence.

\subsection{Dispersion of tracers}

All composites were prepared under identical mixing and moulding conditions. Several samples of polypropylene containing the rare earth oxides in different concentrations were prepared for analysis (Table 2), using a twin screw extruder CLEXTRAL BC21 machine with a screw of $L / D=90$ and $D=25 \mathrm{~mm}$. The extrusion temperature and screw speed were $205^{\circ} \mathrm{C}$ and $120 \mathrm{rpm}$ respectively. The screw and temperature profiles used in this study are supplied in Fig. 2.

The pellets obtained from extrusion were then injected in a Battenfeld Unilog B2/350 Plus injection moulding machine. A general purpose screw was used in the barrel, which was kept at $220^{\circ} \mathrm{C}$. Specimens of $6 \mathrm{~cm}$ of diameter and $2 \mathrm{~mm}$ of thickness were fabricated, for the X-ray fluorescence analysis.

\subsection{X-ray fluorescence device}

The X-ray fluorescence device, developed by NRT, is a test system which allows taking static measurements of the samples spectrum. A schematic of a typical EDXRF (energy dispersive X-ray fluorescence) spectrometer is shown in Fig. 3. The X-ray radiation from the X-ray source passes through a hole onto the sample and then travels to the detector.

The signal from the detector is then processed electronically and sent to the computer, which also controls the X-ray source. The XRF spectra can then be analyzed and used for the separation of the samples containing the tracers.

This EDXRF technique (Havrilla, 1997) is a two-step process that begins with the removal of an inner shell electron of an atom.

Table 2

Characteristics of the traced polypropylene samples.

\begin{tabular}{llcl}
\hline Code PP/tracer_ppm & Tracer & $\begin{array}{l}\text { Mass }(\mathrm{ppm}) \\
\text { composition }\end{array}$ & $\begin{array}{l}\text { Melting } \\
\text { point }\left({ }^{\circ} \mathrm{C}\right)\end{array}$ \\
\hline PP & PP-reference & 0 & 166.7 \\
PP/Nd $\mathrm{NO}_{3} \_1000$ & $\mathrm{Nd}_{2} \mathrm{O}_{3}$ & 1000 & 167.1 \\
PP/Gd $\mathrm{Gd}_{3} \mathrm{O}_{3} 1000$ & $\mathrm{Gd}_{2} \mathrm{O}_{3}$ & 1000 & 166.1 \\
PP/all_250 & $\mathrm{Y}_{2} \mathrm{O}_{3}, \mathrm{CeO}_{2}, \mathrm{Nd}_{2} \mathrm{O}_{3}$, & 250 & 166.2 \\
PP/all_1000 & $\mathrm{Gd}_{2} \mathrm{O}_{3}, \mathrm{Dy}_{2} \mathrm{O}_{3}$, & 1000 & 166 \\
PP/all_1450 & $\mathrm{Er}_{2} \mathrm{O}_{3}, \mathrm{Yb}_{2} \mathrm{O}_{3}$ & 1450 & 165.7 \\
\hline
\end{tabular}

The resulting vacancy is filled by an outer shell electron. The second step is the transition from the outer shell electron orbital to an inner shell electron orbital. The transition is accompanied by the emission of X-ray photon. The fluorescent photon is characteristic of the element and is equal to the difference in energy between the two electron energy levels. Because the energy difference is always the same for given energy levels, the element can be identified by measuring the energy of the emitted photon. In turn, the intensity of the emitted photons determines the concentration of the element. Therefore the measure of the photon energy provides the identification of the element and the intensity of the photon emission provides a measure of the amount of the element.

The emission process is similar to other fluorescent measurement techniques, but it is restricted to the X-ray region of the electromagnetic spectrum that ranges from 4 to over $80 \mathrm{keV}$. The photon energies detected are designated as $\mathrm{K}$, L, or M X-rays, depending on the energy level being filled. For example, $\mathrm{NdK}_{\beta 1}$ represents, for the neodymium element, the transition corresponding to the passage of $\mathrm{M}$ to $\mathrm{K}$ level and 1, the relative intensity of the transition in the series (1, more intense than 2 ). There are as many possible X-ray lines as there are inner shell electrons. However, the most analytically useful and most intense X-ray lines are the $\mathrm{K}$ shell electrons. Although the multitude of emitted X-ray lines could result in complex spectra, the relative low intensities of the lines below the L level allow obtaining a clear spectrum with minimal interference.

The volume of the analyzed sample was $1 \mathrm{~mm}^{3}$. The distance between the sample and the source was $10 \mathrm{~cm}$ and the angle

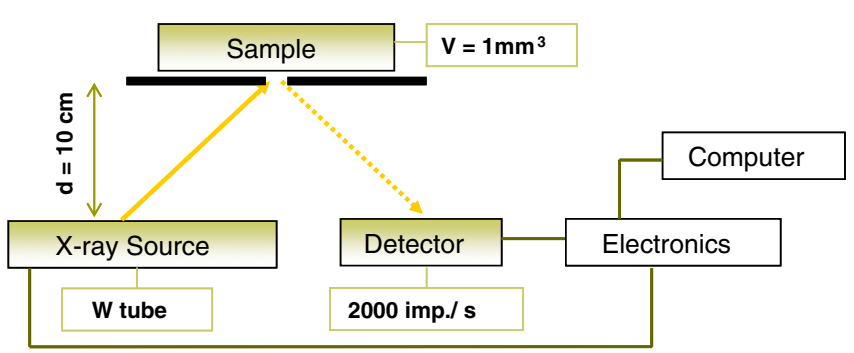

Fig. 3. Schematic of the EDXRF device. X-rays from the tungsten tube pass through a hole on their way to the sample. X-rays from the sample then travel to the "2000 impulsions per second" detector. The signal at the detector is then processed by electronics and sent to a computer for analysing the spectra.

\begin{tabular}{l}
\begin{tabular}{|l|l|l|l|l|l|l|l|l|}
\hline $\begin{array}{c}\text { Zone 1 } \\
80^{\circ} \mathrm{C}\end{array}$ & $\begin{array}{l}\text { Zone 2 } \\
160^{\circ} \mathrm{C}\end{array}$ & $\begin{array}{l}\text { Zone 3 } \\
205^{\circ} \mathrm{C}\end{array}$ & $\begin{array}{l}\text { Zone } 4 \\
205^{\circ} \mathrm{C}\end{array}$ & $\begin{array}{l}\text { Zone } 5 \\
205^{\circ} \mathrm{C}\end{array}$ & $\begin{array}{l}\text { Zone } 6 \\
205^{\circ} \mathrm{C}\end{array}$ & $\begin{array}{l}\text { Zone } 7 \\
205^{\circ} \mathrm{C}\end{array}$ & $\begin{array}{c}\text { Zone } 8 \\
205^{\circ} \mathrm{C}\end{array}$ & $\begin{array}{c}\text { Zone } 9 \\
205^{\circ} \mathrm{C}\end{array}$ \\
\hline
\end{tabular} \\
\hline
\end{tabular}

Fig. 2. Screw and temperature profiles for the extrusion processing. 
$45^{\circ}$. The detection time varied from 1 to $4 \mathrm{~min}$ and the detector could make 2000 counts per second. The X-ray source used was a tungsten tube.

\section{Results and discussions}

\subsection{Detection of tracers and concentration effect}

The first objective of these tests was to prove the detection of the 7 tracers in the polypropylene matrix. Table 3 shows the expected energy of the element composing the tracers. The detection of tracers is separated in two domains. The first one, between 7$20 \mathrm{keV}\left(\mathrm{L}_{\alpha 1}, \mathrm{~L}_{\beta 1}\right.$ of ytterbium and $\mathrm{K}_{\alpha 1}, \mathrm{~K}_{\beta 1}$ of yttrium) and the second between $34-60 \mathrm{keV}\left(\mathrm{K}_{\alpha 1}, \mathrm{~K}_{\beta 1}\right.$ of cerium to ytterbium).

The first samples tested, contained all the tracers $\left(\mathrm{Y}_{2} \mathrm{O}_{3}, \mathrm{CeO}_{2}\right.$, $\mathrm{Nd}_{2} \mathrm{O}_{3}, \mathrm{Gd}_{2} \mathrm{O}_{3}, \mathrm{Dy}_{2} \mathrm{O}_{3}, \mathrm{Er}_{2} \mathrm{O}_{3}$ and $\mathrm{Yb}_{2} \mathrm{O}_{3}$ ) in three different concentrations (PP/all_250, PP/all_1000 and PP/all_1450). The exposure time for the four samples was $1 \mathrm{~min}$. The obtained spectrum is shown in Fig. 4.

As shown in the spectrum, five of the tracers $\left(\mathrm{Y}_{2} \mathrm{O}_{3}, \mathrm{CeO}_{2}\right.$, $\mathrm{Nd}_{2} \mathrm{O}_{3}, \mathrm{Gd}_{2} \mathrm{O}_{3}$ and $\mathrm{Dy}_{2} \mathrm{O}_{3}$ ), at concentration levels of 1000 and $1450 \mathrm{ppm}$, are clearly visible and distinguishable from the "background" sample of 0 ppm by their $\mathrm{K}_{\alpha 1}$ energy line.

For the same five tracers at $250 \mathrm{ppm}$, the fluorescent peak is not sufficiently different from the background in order to make a positive identification.

Concerning the detection of $\mathrm{Er}_{2} \mathrm{O}_{3}$ and $\mathrm{Yb}_{2} \mathrm{O}_{3}$, their $\mathrm{K}_{\alpha 1}$ energy lines (49.12 and $52.38 \mathrm{keV}$ respectively) are emitted in the same range of energy [49-53 keV] as the tungsten source $\left(\mathrm{WK}_{\alpha 1}\right.$ : $59.31 \mathrm{keV}$ ), rescheduled of about 8-9 keV. By using another source, gold for example, this problem can probably be avoided.

Regarding the detection of the $\mathrm{L}_{\alpha 1}$ and $\mathrm{L}_{\beta 1}$ energy lines of $\mathrm{CeO}_{2}$, $\mathrm{Nd}_{2} \mathrm{O}_{3}, \mathrm{Gd}_{2} \mathrm{O}_{3}, \mathrm{Dy}_{2} \mathrm{O}_{3}, \mathrm{Er}_{2} \mathrm{O}_{3}$ and $\mathrm{Yb}_{2} \mathrm{O}_{3}$, a large fluorescent peak appears in the range [5-9 keV] corresponding to these energies.
Consequently it is difficult to distinguish the $\mathrm{L}_{\alpha 1}$ and $\mathrm{L}_{\beta 1}$ energy lines of these elements.

Moreover, the detection of the $\mathrm{L}_{\alpha 1}$ and $\mathrm{L}_{\beta 1}$ energy lines present three additional difficulties:

- They have significantly less fluorescent yield than the K energy lines.

- They are much closer in energy to other elements which might be present (example cerium versus titanium) and thus require a combination of longer exposure times and more sensitive detectors.

- The lower energy of L X-rays are more easily absorbed by air, plastic dust coverings, thin metal foils, that are present in the construction of an "industrial" sorting environment.

\subsection{The overlapping and mass absorption effect}

The second objective of these tests was to assess the probable overlapping and mass absorption of energy lines of different tracers. Four different spectra corresponding to polypropylene with all the tracers, with gadolinium oxide and with neodymium oxide at $1000 \mathrm{ppm}$ and the polypropylene reference are presented in Fig. 5. The exposure time was $1 \mathrm{~min}$.

The samples of neodymium oxide and gadolinium oxide were chosen for the reason that the $K_{\beta 1}$ energy line of neodymium $(42.27 \mathrm{keV})$ is close to the $K_{\alpha 1}$ energy line of gadolinium (42.99 keV) and this small energy difference could lead to overlapping interferences.

In the range [41.5-43.5 keV] a large fluorescent peak is observed. By taking in consideration that the $K_{\beta 1}$ energy line of neodymium is $42.27 \mathrm{keV}$ and the $\mathrm{K}_{\alpha 1}$ energy line of gadolinium is $42.99 \mathrm{keV}$, it is difficult to distinguish which element is contained in the polymer matrix. The overlapping is caused by the small en-

Table 3

X-ray fluorescent energies of the elements (Peltier, 1986).

\begin{tabular}{|c|c|c|c|c|c|c|c|c|}
\hline Energy lines (keV) & $\begin{array}{l}\mathrm{Y}_{2} \mathrm{O}_{3} \\
\mathrm{Y}\end{array}$ & $\begin{array}{l}\mathrm{CeO}_{2} \\
\mathrm{Ce}\end{array}$ & $\begin{array}{l}\mathrm{Nd}_{2} \mathrm{O}_{3} \\
\mathrm{Nd}\end{array}$ & $\begin{array}{l}\mathrm{Gd}_{2} \mathrm{O}_{3} \\
\mathrm{Gd}\end{array}$ & $\begin{array}{l}\mathrm{Dy}_{2} \mathrm{O}_{3} \\
\mathrm{Dy}\end{array}$ & $\begin{array}{l}\mathrm{Er}_{2} \mathrm{O}_{3} \\
\mathrm{Er}\end{array}$ & $\begin{array}{l}\mathrm{Yb}_{2} \mathrm{O}_{3} \\
\mathrm{Yb}\end{array}$ & $\begin{array}{l}\text { Source } \\
\text { W }\end{array}$ \\
\hline $\mathrm{K}_{\alpha 1}$ & 14.96 & 34.71 & 37.36 & 42.99 & 45.99 & 49.12 & 52.38 & 59.31 \\
\hline $\mathrm{K}_{\beta 1}$ & 16.74 & 39.26 & 42.27 & 48.72 & 52.18 & 55.69 & 59.35 & 67.23 \\
\hline $\mathrm{L}_{\alpha 1}$ & 1.92 & 4.84 & 5.23 & 6.06 & 6.49 & 6.95 & 7.41 & 8.40 \\
\hline $\mathrm{L}_{\beta 1}$ & 1.99 & 5.26 & 5.72 & 6.71 & 7.25 & 7.81 & 8.40 & 9.67 \\
\hline
\end{tabular}

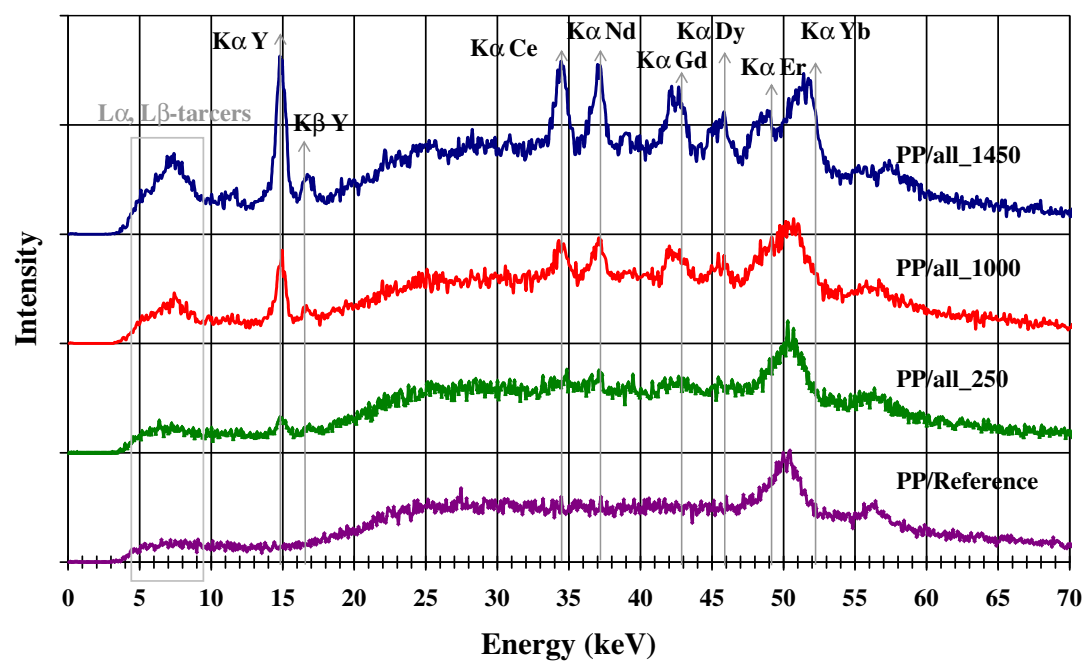

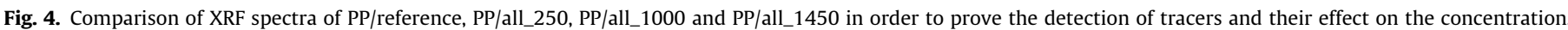


ergy difference between $K_{\beta 1}$ energy line of neodymium and the $K_{\alpha 1}$ line of gadolinium.

This is a problem associated with the detector and which can be resolved by either of the following two options. The first one is to use a detector which has a better resolution than that used for these trials. The other solution may be the simultaneous detection of $K_{\alpha 1}$ and $K_{\beta 1}$ energy lines of gadolinium in order to identify it.

Regarding the mass absorption effect, in the energy range [36.5-38 keV], corresponding to the $K_{\alpha 1}$ energy line of neodymium, the surface of the fluorescent peak is larger in the case of neodymium oxide at $1000 \mathrm{ppm}$ alone than the peak of polypropylene containing all the tracers. This means that the presence of several rare earth oxides at the same time could influence their intensity. This factor should be studied in more details in order to have a better understanding and take it in consideration for the detection, if necessary.

\subsection{The effect of the acquisition time}

During these tests, the effect of the acquisition time in the detection of tracers was also studied. The fluorescent emissions of a sample with $250 \mathrm{ppm}$ of all tracers exposed for 1 and 4 min were compared to $1000 \mathrm{ppm}$ sample exposed for $1 \mathrm{~min}$ (Fig. 6).

The main aim was to look at the difference between a sample exposed for $1 \mathrm{~min}$ and 1 for $4 \mathrm{~min}$, in order to study the effect of the acquisition time. Secondly, we wanted to observe if there is a linear evolution between the detection time and the concentration of the tracer. For that reason, the graph containing the sample of all the tracers at $250 \mathrm{ppm}$ exposed for $4 \mathrm{~min}$ is compared to the sample of all tracers at $1000 \mathrm{ppm}$ exposed for $1 \mathrm{~min}$.

By comparing the graphs of the samples containing all the tracers at $250 \mathrm{ppm}$ at 1 and 4 min exposure time, it appears that for the sample exposed for $4 \mathrm{~min}$, five of the tracers $\left(\mathrm{Y}_{2} \mathrm{O}_{3}, \mathrm{CeO}_{2}, \mathrm{Nd}_{2} \mathrm{O}_{3}\right.$, $\mathrm{Gd}_{2} \mathrm{O}_{3}$ and $\mathrm{Dy}_{2} \mathrm{O}_{3}$ ) are clearly visible and distinguishable from the "background" sample of $0 \mathrm{ppm}$ by their $\mathrm{K}_{\alpha 1}$ energy line compared to the sample exposed for $1 \mathrm{~min}$, in which only three tracers $\left(\mathrm{Y}_{2} \mathrm{O}_{3}, \mathrm{CeO}_{2}\right.$ and $\left.\mathrm{Nd}_{2} \mathrm{O}_{3}\right)$ are distinguishable.

For the samples containing all the tracers at $250 \mathrm{ppm}$ for $4 \mathrm{~min}$ and at $1000 \mathrm{ppm}$ for $1 \mathrm{~min}$, in both case five of the tracers $\left(\mathrm{Y}_{2} \mathrm{O}_{3}\right.$, $\mathrm{CeO}_{2}, \mathrm{Nd}_{2} \mathrm{O}_{3}, \mathrm{Gd}_{2} \mathrm{O}_{3}$ and $\mathrm{Dy}_{2} \mathrm{O}_{3}$ ) are clearly visible and distinguishable from the background by their $\mathrm{K}_{\alpha 1}$ energy line. The difference between them is that in the case of the sample containing all the tracers at $1000 \mathrm{ppm}$ for $1 \mathrm{~min}$, the surface of the fluorescent peak

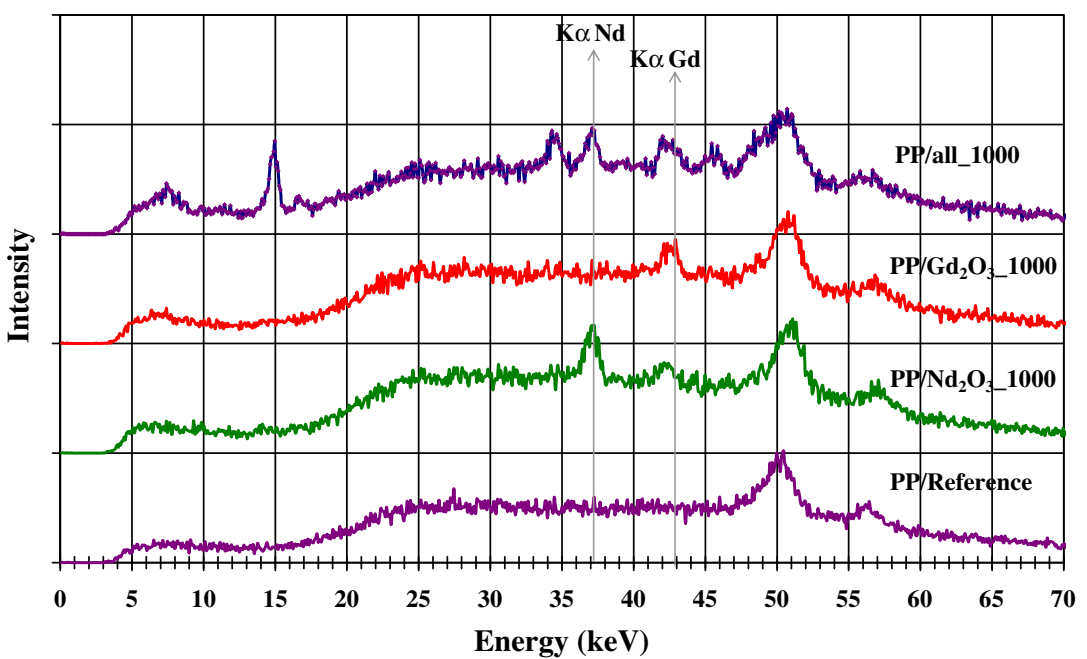

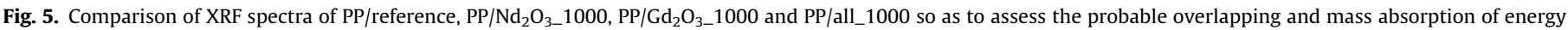
lines between different tracers.

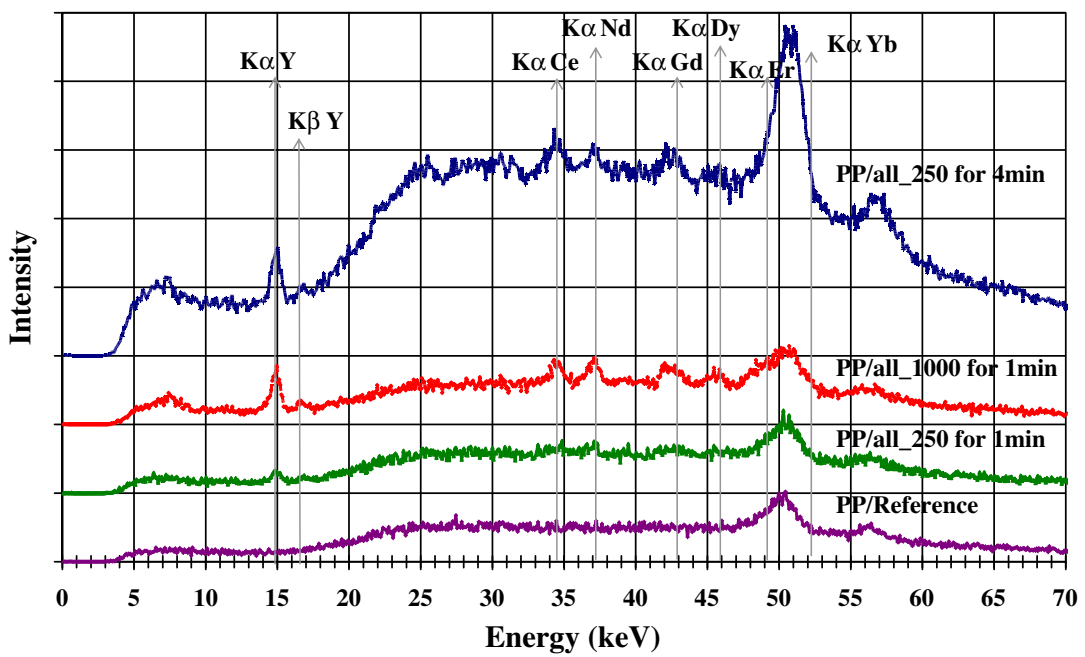

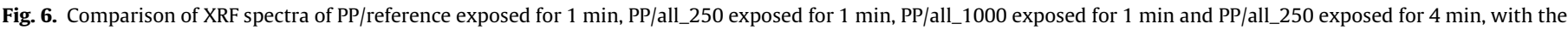
aim of studying the effect of the acquisition time. 
is superior to the one of the sample of all the tracers at $250 \mathrm{ppm}$ for $4 \mathrm{~min}$. The advantage of this last one is that the $\mathrm{K}_{\beta 1}$ energy line of neodymium and the $K_{\alpha 1}$ of gadolinium are more easily distinguished between them compared to the sample containing all the tracers at $1000 \mathrm{ppm}$ for $1 \mathrm{~min}$ exposition time.

The conclusion reached from these tests is that by increasing the acquisition time, the fluorescent peak is more distinguishable from the background and therefore the level of accuracy in identification is increased.

\section{Conclusion and further research}

The majority of post-consumer plastic wastes is sent to landfill sites for disposal. The automotive and electrical industries are currently the worst performers, concerning the recycling of plastics, partly due to the complexity of the waste material that these sectors produce. The existing automatic sorting techniques are not applicable to dark plastics and can not provide sorted plastics into individual types and grades.

The originality of this work is to propose an X-ray fluorescence detection system based one the use of tracers, for the identification of plastics. The use of a tracer system offers many benefits in the sorting of plastics. The tracer system can provide specific/positive identification versatility and increase the efficiency of sorting and purity of the sorted fractions. It can also provide high speed identification of plastic material and solve the problem of identifying dark plastics.

This work shows that by using the XRF test system device, it was possible to detect 5 of the 7 tracers tested at the concentration level of $1000 \mathrm{ppm}$. The two parameters, concentration level and acquisition time, will play an important role in the development of an industrial device. Some improvements have to be made in order to reduce the acquisition time and the concentration level of the tracers. For this reason further work is under progress with the objective of developing a pilot plant devoted to the optimization of these two parameters.

\section{Acknowledgements}

The authors would like to thank National Recovery Technologies Inc. for helping us to carry out the tests in their X-ray fluorescence device, the French Environment and Energy Management Agency (ADEME - www.ademe.fr) and the French Industry-University Cooperative Research Network on Waste (RECORD - <www. record-net.org >) for their contribution to the funding of this work and for providing industrial orientations and scientific supervision to the research.

\section{References}

Ahmad, S.R., 2004. A new technology for automatic identification and sorting of plastics for recycling. Environ. Technol. 25 (10), 1143-1149.

Ahmad, S.R., 2000. Marking of products with fluorescent tracers in binary combinations for automatic identification and sorting. Assem. Autom. 20 (1) 58-64.

Ahmad, S.R., 1992. Partners wanted for polymer research project. Mater. Recycl. Weekly (UK) 14.

Alam, M.K., Stanton, S.L., Hebner, G.A., 1994. Near-infrared spectroscopy and neural networks for resin identification. Spectroscopy 9 (2), 30-40.

European Parliament, 2003. Directive 2002/96/EC of the European parliament and of the council of 27 January 2003 on waste electrical and electronic equipment.

European Parliament, 2000. Directive 2000/53/EC of the European parliament and of the council of 18 September 2000 on end-of-life vehicles.

Florestan, J., Lachambre, A., Mermilliod, N., Boulou, J.C., Marfisi, C., 1994. Recycling of plastics: automatic identification of polymers by spectroscopic methods. Resour., Conserv. Recycl. 10 (1-2), 67-74.

Froelich, D., Maris, E., Haoues, N., Chemineau, L., Renard, H., Abraham, F. Lassartesses, R., 2007. State of the art of plastic sorting and recycling: feedback to vehicle design. Miner. Eng. 20 (9 SPEC. ISS.), 902-912.

Havrilla, G.J., 1997. Handbook of Instrumental Techniques for Analytical Chemistry, pp. 459-479.

Hedrick, J.B., 1988. Availability of rare earths. Am. Ceram. Soc. Bull. 67 (5), 858-861.

Kenny, G.R., Bruner, R.S., 1994. Experience and advances in automated separation of plastics for recycling. J. Vinyl Addit. Technol. 16 (3), 181-186.

Lauwerys, R.R., Haufroid, Vés, Huet, Pés, Lison, Dés. impr. 2007. Toxicologie industrielle et intoxications professionnelles [texte imprimé]. Issy-lesMoulineaux: Elsevier, Masson.

Maestro, P., Huguenin, D., 1995. Industrial applications of rare earths: which way for the end of the century? J. Alloys Compd. 225, 520-528.

Mankosa, M.J., Luttrell, G.H., 2005 inventors; Plastic material having enhanced magnetic susceptibility, method of making and method of separating.

Moore, S., 1999. Infrared scanner affords easy plastic identification. Mod. Plast. (NY) 76, 32-33.

Morteani, G., 1991. The rare earths: their minerals, production and technical use. Eur. J. Mineral. 3 (4), 641-650.

Olofsson, M., Sundberg, J., Sahlin, J., 2005. Evaluating waste incineration as treatment and energy recovery method from an environmental point of view. In: 13th Annual North American Waste to Energy Conference, NAWTEC13; 23 May 2005 through 25 May 2005; Orlando, FL, 175 p.

Patel, M.K., Jochem, E., Radgen, P., Worrell, E., 1998. Plastics streams in Germany an analysis of production consumption and waste generation. Resour. Conserv. Recycl. 24 (3-4), 191-215.

Peltier, A., 1986. Exposition aux poussières de terres rares. Report nr. 122.

Simmons, B.A., Overton, B.W., Viriot, M., Ahmad, S.R., Squires, D.K., Lambert, C., 1998. Fluorescent tracers enable automatic identification and sorting of waste plastics. Br. Plast. Rubber 4, 6, 8 .

Zoboli, R., 1998. Implications of environmental regulation on industrial innovation: The case of end-of-life vehicles. Implications of Environmental Regulation on Industrial Innovation: The Case of End-of-Life Vehicles. 